Int. J. Morphol.,

35(1):265-272, 2017

\title{
Quantification by Quadrants of the Distortion Present in Conventional Panoramic Radiograph
}

\author{
Cuantificación por Cuadrantes de la Distorsión Presente \\ en la Radiografía Panorámica Convencional
}

\begin{abstract}
Janneth Zúñiga ${ }^{1}$
ZÚÑIGA, J. Quantification by quadrants of the distortion present in conventional panoramic radiograph. Int. J. Morphol., 35(1):265$272,2017$.

SUMMARY: The panoramic radiograph constitutes the "gold standard" for any clinical evaluation in dentistry. It has been universally accepted that it has a global distortion of $25 \%$ due to magnification. The present study was carried out to determine more precise percentages of distortion, and to find out whether the distortion was due to magnification or minimization. Thirty skulls with their mandibles were divided by two horizontal and four vertical planes in ten quadrants. Wires of different lengths were fixed in each of these quadrants. A panoramic radiograph was taken for each skull. The lengths of the wires measured in the images (distorted value) were compared to the actual lengths of the wires (real value). The concordance correlation coefficient was calculated. Due to high bone density, in the upper lateral quadrants ( 1 and 5) no measurements could be obtained. In the intermediate upper quadrants ( 2 and 4$)$ and in the median lower quadrant (8), the horizontal measurements were minimized, while in the intermediate inferior quadrants (7 and 9) and in the lateral inferior quadrants ( 6 and 10$)$, the horizontal measurements were magnified. In both the upper and the lower quadrants (2, 3 , $4,6,7,8,9,10)$ all the vertical measurements were magnified. The percentage of distortion in each quadrant for the horizontal and vertical measurements was reported. The percentage of distortion in a panoramic radiograph of the face varies from one region to another and can be due to either magnification or minimization.
\end{abstract}

KEY WORDS: Panoramic radiograph; Orthopantomograph; Distortion.

\section{INTRODUCTION}

The panoramic radiograph constitutes the "Gold Standard" for the initial assessment carried out in dentistry because it allows the observation of normal and abnormal bony and dental tissue of the maxilla and mandible. With this type of X-ray it is possible to identify and study specific anatomic structures, among these the location of the mandibular canal in relation to the third molars (Sedaghatfar, 2005), the mental foramen (Mohamed et al., 2016), and the position of the teeth (Sandhu \& Kaur, 2008). It serves to evaluate alterations caused by missing or supernumerary teeth, alterations in the dental morphology, bone alterations like osteonecrosis (Treister et al., 2009) and osteoporosis (Gaur et al., 2013), bone fractures (Roth et al., 2005), facial asymmetries (Farman, 2006), and dental-facial anomalies. It is also useful for corpse identification (Tohnak, 2007) and for predicting gender and age (Bhardwaj et al., 2014). Finally, it is a valuable tool for comparing post-surgical results with the previous disturbance (Mazzonetto \& Allais de Maurette, 2005) and oral implant procedures (Hallman, 2002).
It is of great importance to know the precise dimensions and degrees of distortion of the panoramic radiograph, as it is a fundamental tool used from the beginning of the diagnostic process. Also, it is necessary to understand how the distortion behaves; for example, if it is uniform throughout the X-ray image, as it has until now been assumed, or if it varies from one region to another of the cranium. The position of the patient on the orthopantomograph is, to a great extent, responsible for the distortion in the panoramic radiograph; neck flexion and extension result in different positions of the head, and this is more severe in edentulous than in dentate patients (Batenburg et al., 1997; Rondon et al., 2014). This inadequate positioning of the patient results in varying degrees of distortion throughout the different areas of the face, especially in the lateral regions. Some regions may also appear distorted due to the difference between film speed and projection speed.

Panoramic radiographs are also affected by

${ }^{1}$ Professor at the Universidad del Valle, Department of Morphology, Cali, Colombia. 
displacement. Horizontal and vertical measurements are reliable as long as they do not cross the median plane of the body and are made on only one side (Catic et al., 1998). The horizontal distances are non-reliable as a result of the change in the central angle with which the X-rays are directed upon the curved part of the mandible, whereas the vertical measurements have an adequate precision (Larheim et al., 1984).

Among the different devices used for taking panoramic radiographs, the distortion factors vary mainly because of the geometric projections used by each one. These variations, among other causes, may be generated by the type of equipment used, the specimen employed and the protocol followed for the correct positioning of the specimen in such equipment. Schulze et al. (2000) conducted a study to determine the precision and accuracy of the measurements taken from 70 digital panoramic X-ray films of a cranium placed in seven different positions, finding that the distortion varied in the horizontal as well as in the vertical measurements, generally being the vertical measurements less reliable than the horizontal ones. Additionally, they determined three different factors of error: the first, the systematic error due to the method used, the second due to the intraobserver variability, and the third due to the magnification generated by the equipment.

The purpose of the present research work was to determine the percentage of distortion, due to magnification or minimization, found in ten different quadrants of the face.

\section{MATERIAL AND METHOD}

Cross-sectional study. Thirty (30) dry human skulls from unidentified cadavers were obtained from the Department of Morphology of the Universidad del Valle in Cali, Colombia, with the following inclusion criteria: (i) existence of the corresponding mandible, preferably with teeth, for each skull, (ii) good state of preservation of both the skull and mandible to allow for adequate measurements.

To take the panoramic radiograph, the skull was placed in anatomical position, simulating that of a patient. This position was attained by bilaterally placing a thick, non-deforming foam support $\left(1 \mathrm{~cm}^{3}\right)$ at the pterion, thus simulating the presence of soft tissue that serves as support for the orthopantomograph. The skull was placed with the Frankfort plane (Lundström \& Lundström, 1995) parallel to the floor and the axis of the light beam in the median plane. In the edentulous skulls a support was placed interdentally to leave an intercrestal space of approximately $15 \mathrm{~mm}$; for this purpose, thick, non-deforming foam wedges were used to simulate the presence of teeth, thus maintaining the vertical dimension of the skull and the stability of the temporomandibular articulation. Additionally, to improve the stabilization of this articulation, a deformable $3 \mathrm{~mm}$ thick foam wedge was placed between the articular surfaces in replacement of the articular disc (Fig.1).
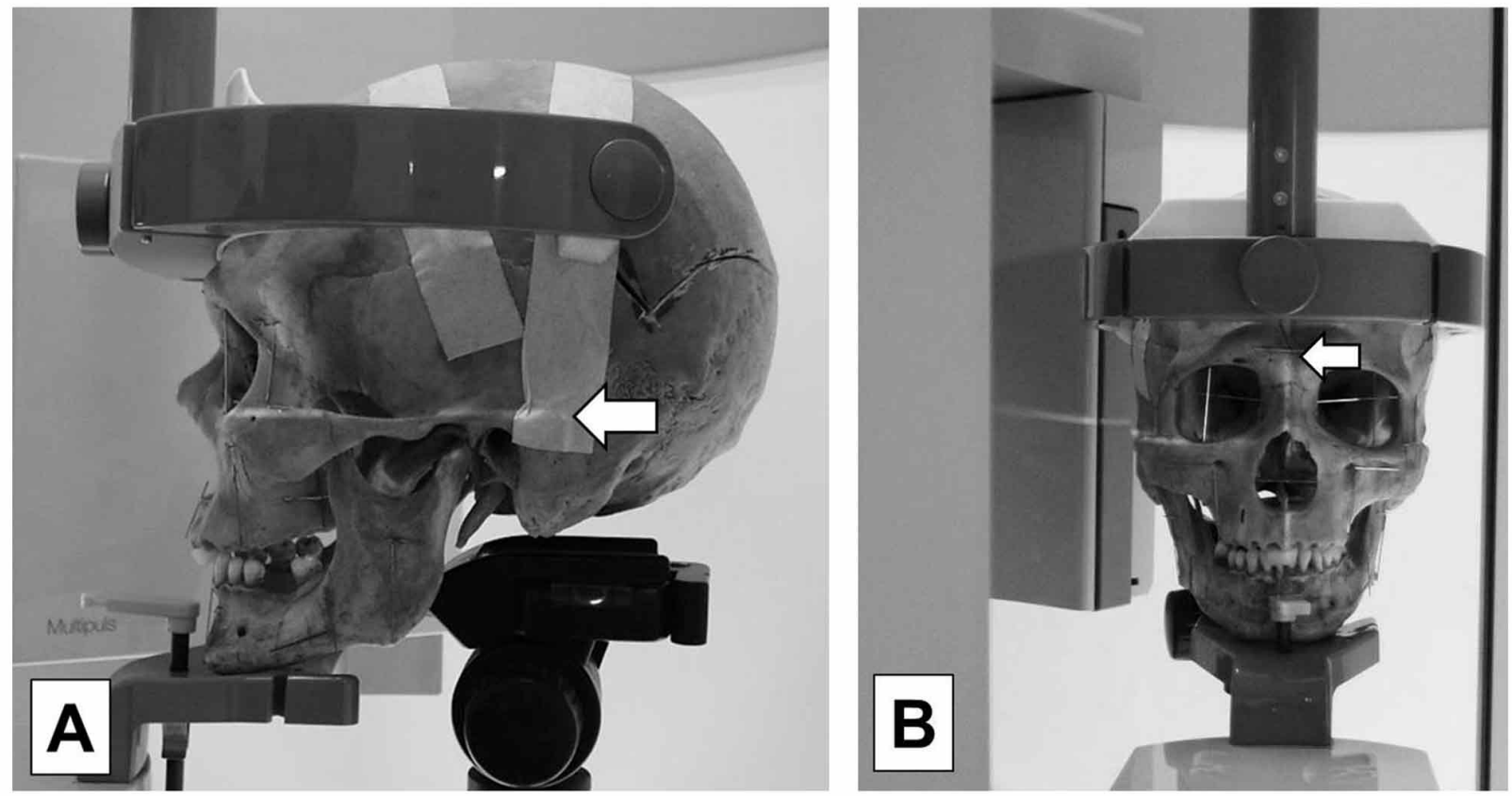

Fig. 1. Positioning of the skull for the taking of radiographs in panoramic projection. A, The light marks indicate the Frankfort plane of the skull (white arrow). B, The light marks indicate the median plane of the skull (white arrow). 
Definition of the areas, Regions and Quadrants in Which the Skull and the Mandible were Divided. The articulated skull was divided horizontally into superior and inferior craniofacial areas and vertically in median, right and left intermediate, and right and left lateral regions.

\section{Craniofacial Areas}

a. Superior Area: Extended between the horizontal that passes through the most sloping part of the infraorbital borders (Plane A) and the horizontal that is equidistant from the alveolar bone crests of the maxilla and of the mandible (Plane B), which represents the occlusal plane.

b. Inferior Area: Corresponded to the mandible, extending from plane B to the horizontal traced parallel to the inferior border of the mental symphysis (Plane $\mathrm{C}$ ).

Cranio-facial regions. Vertical lines were traced perpendicular to planes A, B, and C. One set of lines were traced passing through the most medial border of the infraorbital foramens (plane I for the right side and plane I' for the left side). Another set of lines passed through the inferior border

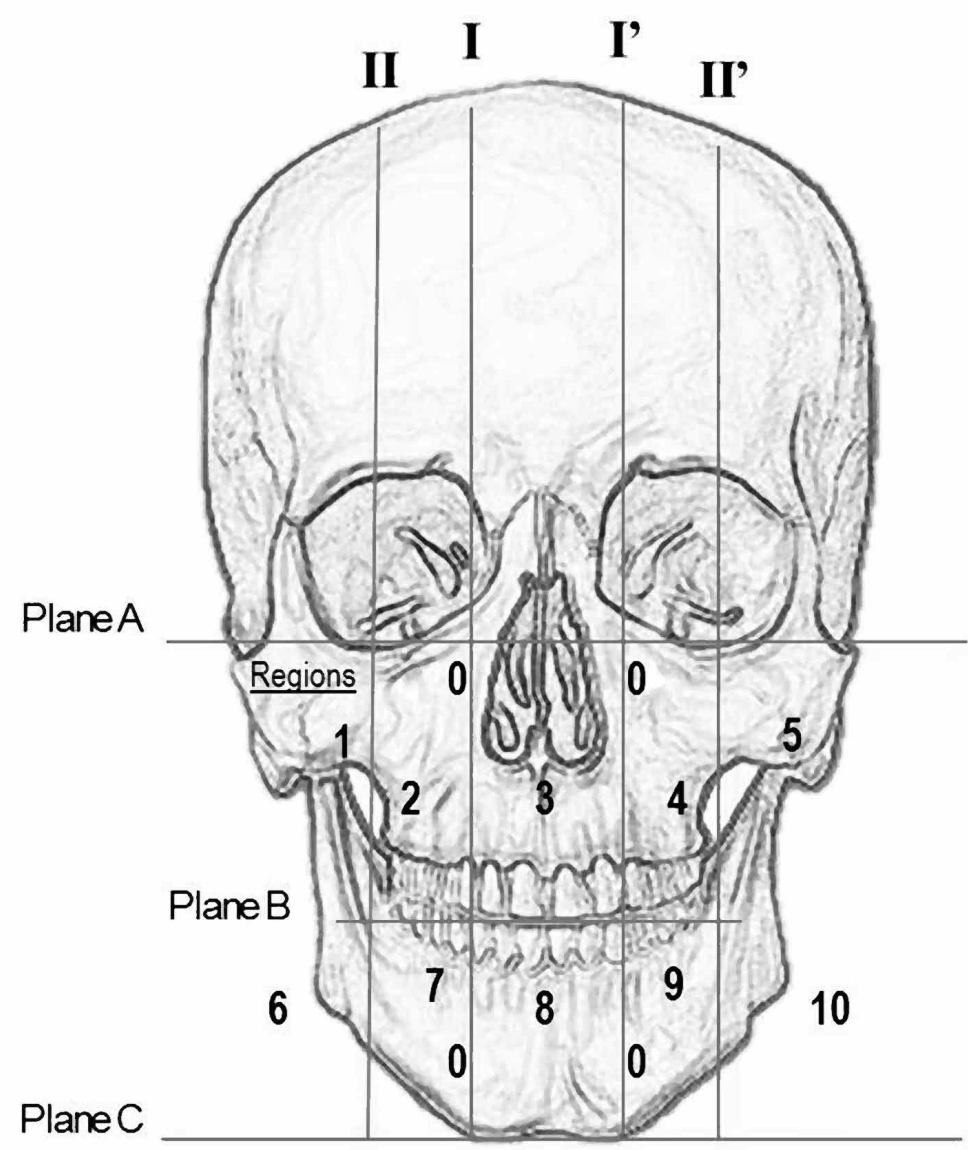

of the zygomaticomaxillary suture, which generally coincides with the anterior border of the mandibular branch (plane II for the right side and plane II' for the left side).

c. Median region: Extended between planes I and I'.

d. Intermediate right and left regions: Extended on each side between planes I and II, and I' and II', respectively. e. Right and left lateral regions: Extended laterally to planes II and II. It is important to clarify that on the X-ray the lateral region of the superior third comprises mainly the zygomatic arch, and the inferior third contains the condylar process and the mandibular ramus. The aforementioned is because the zygomatic arch is not on the same plane as the latter structures.

With the areas and the regions thus delineated, ten quadrants were defined and numbered from 1 to 10 , successively from top to bottom and from right to left, as shown in Fig. 2. In each of the delimited skull quadrants stainless steel wires were placed to serve as a reference for the measurements. They were set in the least irregular part of the quadrant, with the exception of quadrant 3 in which the horizontal wire crossed the median plane at the level of the pyriform aperture of the nasal cavity, supported on the root of the right and left inferior nasal conchae (Fig. 3). The radiographs in panoramic projection were taken with an ORTHOPHOS Plus Ceph (Sirona Dental Systems $\mathrm{GmbH})$. The radiographs were always taken by the same two technicians. (Fig. 4).

Measurements In the Dry Skulls and X-Ray Films. The measurements of the wires in the dry skulls (real value) and in the X-rays films (distorted value) were taken with a digital caliper with a resolution of $0.01 \mathrm{~mm} / 0.0005$ ", precision of $+-0.02 \mathrm{~mm} / 0.001$ " and repetitiveness of 0.01 $\mathrm{mm} / 0.0005$ ". Calibration was performed after every five measurements with a compass (KLS Martin) with extra fine and straight tips. The measurements obtained from the real specimen as well as from the X-ray films were repeated in those cases in which the data seemed erroneous.

Statistical Analysis. The lengths of the wires measured in the images (distorted value) were compared to the actual lengths of the wires (real value). The concordance correlation coefficient (CCC) for these two variables was calculated. The CCC values close to 1 indicated a maximum concordance between both measurements.

Fig. 2. Cuadrants for Radiographs in panoramic projection. 


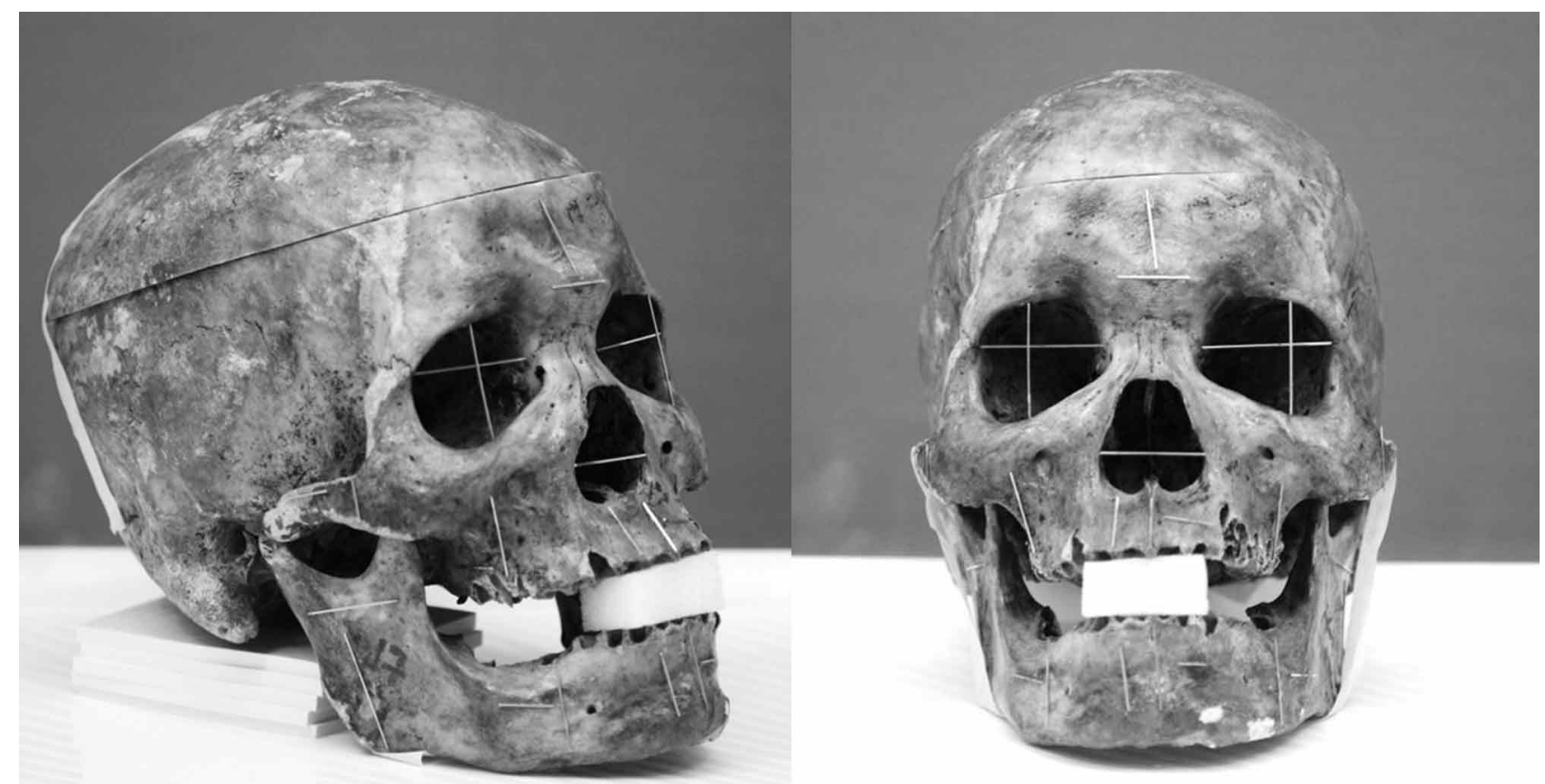

Fig. 3. Positioning of the steel wires on the skull.

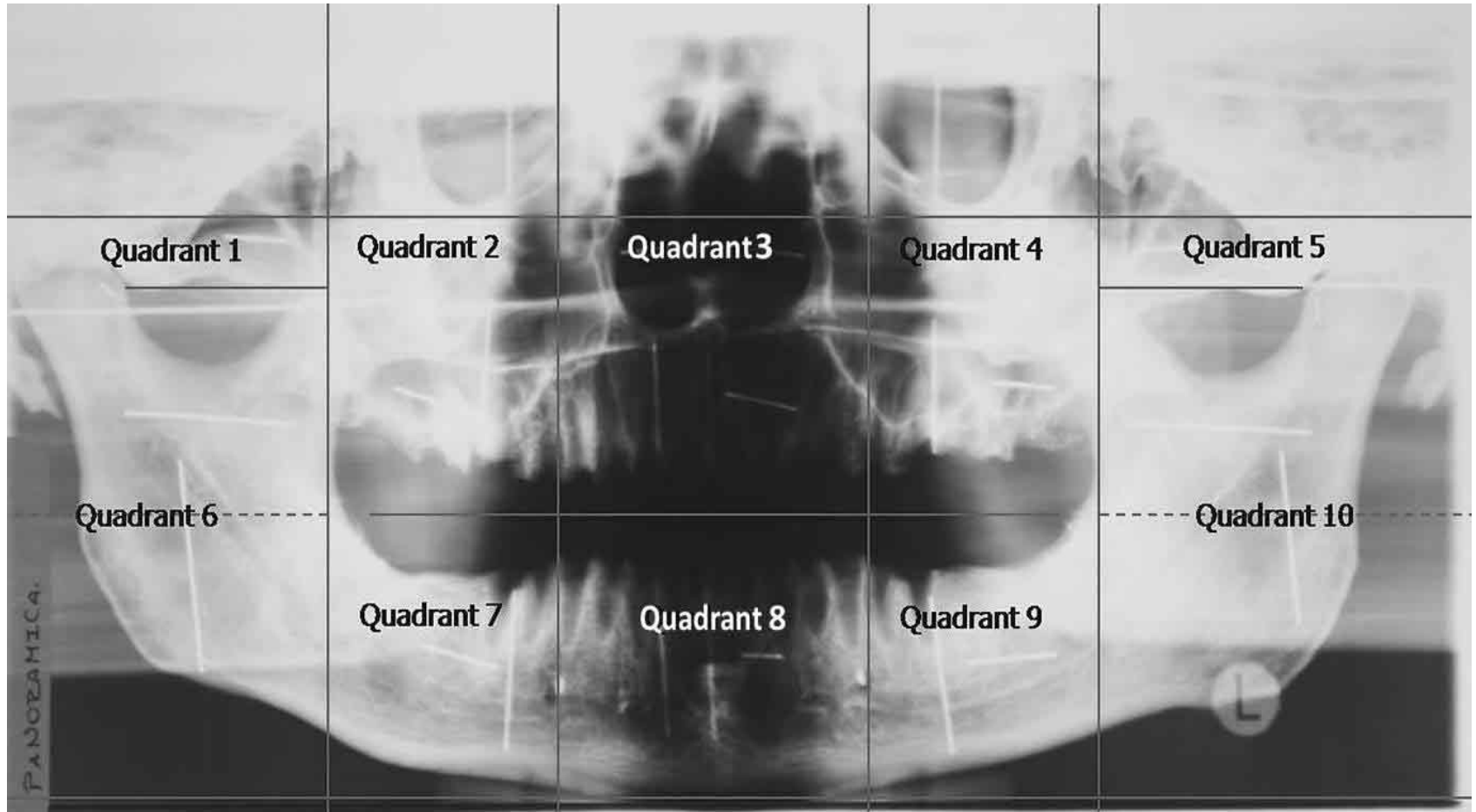

Fig. 4. Radiograph in panoramic projection. 


\section{RESULTS}

Due to space restrictions, all the graphs of the results are not presented and only a reliable and an unreliable quadrant are shown. All the data obtained are summarized in Table I and Table II.
Example: Quadrant 1 Vertical Measurement. The Concordance Correlation Coefficient (CCC) is 0.1295, which indicates that the agreement is low and the median of the differences between the real and the X-ray measurements (d) is unreliable.

Quadrant 2 Vertical Measurement . The CCC is 0.8672 with a Confidence Interval of the CCC (ICccc) between

Table I. Vertical measurements in panoramic radiographs.

\begin{tabular}{cccccccc}
\hline & \multicolumn{3}{c}{ Confidence Interval of CCC } & \multicolumn{3}{c}{$\begin{array}{c}\text { Difference Limits } \\
\text { Quadrant }\end{array}$} & \multicolumn{3}{c}{ (ICccc) } & & & \\
\hline$\#$ & Superior & Median & Inferior & Superior & Median & Inferior & Concept \\
\hline 1 & EEEEE & EEEEE & EEEEE & EEEEE & EEEEE & EEEEE & Unreliable \\
2 & 0.9465 & 0.8672 & 0.7880 & 9.30 & 6.47 & 3.63 & Reliable \\
3 & 0.9138 & 0.8379 & 0.7620 & 19.52 & 17.30 & 15.09 & Reliable \\
4 & 0.9450 & 0.8752 & 0.8054 & 10.02 & 7.63 & 5.24 & Reliable \\
5 & EEEEE & EEEEE & EEEEE & EEEEE & EEEEE & EEEEE & Unreliable \\
6 & 0.9134 & 0.8413 & 0.7693 & 17.52 & 15.64 & 13.77 & Reliable \\
7 & 0.9317 & 0.8687 & 0.8058 & 20.43 & 16.52 & 12.62 & Reliable \\
8 & 0.8998 & 0.8196 & 0.7393 & 22.48 & 19.37 & 16.26 & Reliable \\
9 & 0.9027 & 0.8193 & 0.7359 & 20.92 & 17.60 & 14.27 & Reliable \\
10 & 0.8903 & 0.8068 & 0.7233 & 16.24 & 14.73 & 13.21 & Reliable \\
\hline
\end{tabular}

* Percentage values (\%) with negative sign represent minimization and percentage values (\%) without a sign represent magnification of the image.

Table II. Horizontal measurements in panoramic radiographs.

\begin{tabular}{lccccccc}
\hline Quadrant & \multicolumn{3}{c}{$\begin{array}{c}\text { Confidence Interval of CCC } \\
\text { (ICccc) }\end{array}$} & \multicolumn{3}{c}{$\begin{array}{c}\text { Difference Limits } \\
\text { (\%) } *\end{array}$} \\
\hline$\#$ & Superior & Median & Inferior & Superior & Median & Inferior & Concept \\
\hline 1 & EEEEE & EEEE & EEEEE & EEEEE & EEEE & EEEEE & Unreliable \\
2 & 0.9772 & 0.9235 & 0.8698 & 1.63 & -1.97 & -5.56 & Reliable \\
3 & 0.7102 & 0.5417 & 0.3732 & 8.58 & 4.40 & 0.21 & Unreliable \\
4 & 0.9453 & 0.8393 & 0.7332 & -1.68 & -6.23 & -10.77 & Reliable \\
5 & EEEEE & EEEE & EEEEE & EEEEE & EEEE & EEEEE & Unreliable \\
6 & 0.9130 & 0.8099 & 0.7068 & 11.97 & 9.17 & 6.37 & Reliable \\
7 & 0.9848 & 0.9474 & 0.9100 & 5.89 & 3.34 & 0.78 & Reliable \\
8 & 0.9643 & 0.8872 & 0.8102 & 0.06 & -5.42 & -10.90 & Reliable \\
9 & 0.9873 & 0.9548 & 0.9223 & 3.46 & 0,54 & -2.37 & Reliable \\
10 & 0.9800 & 0.9334 & 0.8869 & 4.22 & 1.90 & -0.42 & Reliable \\
\hline
\end{tabular}

* Percentage values $(\%)$ with negative sign represent minimization and percentage values $(\%)$ without a sign represent magnification of the image.

0.7880 and 0.9465 , which indicates that the agreement is high and the median of the differences between the X-ray measurements and the real measurements (d) is reliable, with an average value of $1.57 \mathrm{~mm}$ and a $95 \%$ Confidence Interval (IC) of $0.88 \mathrm{~mm}-2.26 \mathrm{~mm}$. In this quadrant, the X-ray measurement is greater than the real one, which represents a magnifying percentage of $6.47 \%$, where the limits expressed in percentages are $3.63 \%$ and $9.30 \%$.

\section{DISCUSSION}

The distortion in the panoramic radiograph is routinely considered to be of $25 \%$ due to magnification and it is assumed to be constant throughout the whole image. In quadrants 1 and 5, where there is superimposition of the zygomatic bone with the zygomatic arch and with the mastoid process, the 
radiopacity of the bones was similar to that of the steel wires placed on them. The measurements taken in these quadrants were therefore not reliable because the anatomical structures do not actually have the dimension they appear to have on the X-ray film, or its location is inexact. The great distortion generated in these quadrants may be due to the displacement of the scan trajectory of the $\mathrm{X}$-ray projector.

The horizontal measurement in quadrant 3 , which was obtained by measuring the distance from side to side in the pyriform aperture of the nasal cavity at the level of the root of the inferior nasal conchas, yielded a moderate CCC implying that it is an unreliable measurement. In this region, the facial anatomy changes drastically from the right side to the left and vice versa. The fact that the median line is crossed in this quadrant may have repercussions on the low coefficient found, a similar situation to that reported by Catic (Catic' et al.).

The CCC for the other quadrants was high and the media of the differences between the distorted values and the real values (d) was reliable, which allowed determining the percentage of magnification or minimization for each measurement. In quadrants 2,4 and 8 the horizontal measurements were minimized and in quadrants 6, 7, 9, and 10 they were magnified. Distortion in these horizontal measurements, although of the same type (magnification or minimization), was different in the equivalent quadrants of each side of the face. In the maxilla, the minimization percentage was lower on the right side than on the left side, while in the mandible the magnification was lower on the left side compared to the right. All the vertical measurements in these quadrants $(2,3,4,6,7,8,9$ and 10) were magnified, and were similar to the equivalent quadrants of each side of the skull. The intermediate quadrants of the maxilla (quadrants 2 and 4) were minimized, while in the mandible (quadrants $6,7,9$ and 10) they were magnified. Also, there was greater magnification in the vertical measurements of the mandible than in the corresponding quadrants of the maxilla.

The differences discussed above could be explained by the fact that the $\mathrm{X}$-rays always affect the vertical wires in the same direction, while on the wires placed horizontally, the angle of the rays changes from one point to another. The X-ray emitting source is initially placed on the right side of the face, while the receptor film plate is on the left side. The source shifts behind the head towards the left side of the face and the film plate shifts in front of the face to the right side. This trajectory, added to the quite varied osseous morphology, prevents the ray from always perpendicularly penetrating a structure, which for the case of the wire. This makes the size of the wire to be sometimes diminished and other times augmented. The consistency of these changes leads to obtaining high Concordance Correlation Coefficients, indicating that the measurements in these quadrants are statistically reliable.

Different authors state that horizontal measurements on panoramic radiographs are not particularly reliable due to a non-linear variation in the magnification of the objects found at different depths or as a result of the change in the central angle to compensate for the curvature, in this case of the mandible (Larheim et al.; Laster et al., 2005). However, the results of this study show that although there is greater variability in the magnification or minimization, the reliability is high or very high because the value of CCC is above 0.8 .

Researchers have studied the magnitude of the vertical distortion in panoramic radiographs by measuring the vertical length of the superior and inferior premolars and molars to subsequently compare it with the real length of the teeth. They have found that the magnification is similar on the right and left sides (Yitschacky et al., 2004), which is similar to the results of the present study. However, in these studies the magnification was greater in the maxilla than in the mandible, contrary to what was found in the present work. Nonetheless, it has to be taken in consideration that the measurements made in the present study were not of the teeth, whose anatomy can have multiple variations, but instead they were taken from steel wires placed over the osseous anatomical structures.

The localization of structures in the quadrants of high or very high reliability, taking in consideration the percentage of magnification or minimization present in them, may be very useful. Some of the regions in which reliable measurements can be made are the ones related to the base of the maxillary sinus and the nasal cavity, the infraorbital, mental, and mandibular foramens, the mandibular canal, the lingula of the mandible, the sigmoid notch of the mandible, or the teeth (especially the dental length). The aforementioned can be used to locate the vasculo-nervous structures related to the osseous structures present in such regions.

Studying facial asymmetries in panoramic radiographs results somewhat unreliable if it is considered that for the horizontal measurements the distortion is not similar in the right and left sides. It is obvious that a facial asymmetry cannot be diagnosed based solely on this type of radiograph; nevertheless, if it is the only diagnostic 
aid initially available, it is of upmost importance to apply the percentages of distortion reported in this current work. In this respect, Laster et al., found poor reliability in panoramic radiographs to compare measurements between the right and left sides of the mandible. Other researchers suggested that this type of radiographs could be a diagnostic aid for problems dealing with the temporomandibular articulation, and even the former suggested that discrepancies of more than $6 \%$ in the difference between the heights of the condylar processes could be considered asymmetries (Habets et al., 1987; Turp \& Vach, 1996). Fallon et al. (2006) found such great differences between the real morphology of the mandibular condyle as compared to that of the panoramic X-ray film, that they stated that the data to be used for diagnostic purposes is quite limited.

The results of the present study show that the panoramic radiograph is a useful diagnostic tool, but that its benefits can be further increased if the image is divided into ten specific quadrants and the distortion percentages are taken into account for each of these. Furthermore, it is advised to avoid making linear measurements in those quadrants where reliability was found to be null, low or moderate; this with the purpose of avoiding possible lesions of soft tissues related to osseous structures or for adequately planning a treatment.

An alternative to obtaining greater diagnostic accuracy is the use of tomography. In general, this tool offers better visualization of the anatomic structures without the superimposition of images, with an apparent ratio of 1:1 between the real structure and the image, and allows for 3-D reconstructions. Nonetheless, its relatively high cost becomes a barrier to many patients. For this reason, extracting the greatest amount of information from simple X-ray films is invaluable for health professionals.

In conclusion as a general rule, the vertical measurements of the panoramic radiograph were more reliable than the horizontal ones. The distortion found for the vertical measurements was always of magnification, while the horizontal measurements were magnified in some quadrants and minimized in others. In the horizontal measurements the distortion percentages varied from one side of the skull to the other; while in the vertical measurements they were similar. For the vertical measurements, the mandible presented a greater percentage of magnification than that in the corresponding quadrants of the maxilla. It is evident that the distortion present in the panoramic radiograph is not equal in each of the quadrants in which the skull was divided; for this reason, the distortion cannot be standardized into a sole percentage, nor can it be categorized as magnification in a generalized manner.

\section{ACKNOWLEDGEMENTS}

This research work was funded by the Vice-rectory of Research of the Universidad del Valle. Thanks to Professor Elizabeth Peña for being my guide and teacher in the world of anatomy.

ZÚÑIGA, J. Cuantificación por cuadrantes de la distorsión presente en la radiografía panorámica convencional. Int. J. Morphol., 35(1):265272, 2017.

RESUMEN: La radiografía panorámica constituye el "gold standard” para cualquier valoración clínica en odontología. Universalmente ha sido aceptado que esta radiografía presenta una distorsión por magnificación en cualquier región de $25 \%$. La presente investigación determina 10 diferentes regiones del cráneo divulgando porcentajes de distorsión más precisos y para aclarar si la distorsión fue por magnificación o por minimización. Treinta cráneos con sus mandíbulas fueron divididos por dos planos horizontales y cuatro verticales en 10 cuadrantes y en cada una de estas se fijaron alambres de acero de diferentes longitudes en posición vertical y horizontal. Se tomó una radiografía panorámica a cada cráneo y con un calibrador digital se midieron los alambres sobre los cráneos (valor real) y sobre las radiografías (valor distorsionado). El Coeficiente de Correlación de Concordancia fue calculado. Debido a la alta densidad ósea, en los cuadrantes laterales superiores ( 1 y 5) las medidas no pudieron ser obtenidas. En los cuadrantes superiores intermedios (2 y 4) y en el cuadrante inferior mediano (8) las medidas horizontales son minimizadas, mientras en los cuadrantes inferiores intermedios ( 7 y 9) y en los cuadrantes inferiores laterales (6 y 10) las medidas horizontales son magnificadas. Para las medidas verticales en cualquiera de los cuadrantes superiores e inferiores $(2,3,4,6,7,8,9,10)$ todas las medidas son magnificadas. El porcentaje de distorsión en cada cuadrante para la medida horizontal y vertical es reportada. El porcentaje de distorsión en la radiografía panorámica varía desde una región a otra de la cara y puede ser de magnificación o minimización.

PALABRAS CLAVE: Radiografía panorámica; Ortopantomografía; Distorsión. 


\section{REFERENCES}

Batenburg, R. H.; Stellingsma, K.; Raghoebar, G. M. \& Vissink, A. Bone height measurements on panoramic radiographs: the effect of shape and position of edentulous mandibles. Oral Surg. Oral Med. Oral Pathol. Oral Radiol. Endod., 84(4):430-5, 1997.

Bhardwaj, D.; Kumar, J. S. \& Mohan, V. Radiographic evaluation of mandible to predict the gender and age. J. Clin. Diagn. Res., 8(10):ZC669, 2014.

Catic, A.; Celebic, A.; Valentic-Peruzovic, M.; Catovic, A.; Jerolimov, V. $\&$ Muretic, I. Evaluation of the precision of dimensional measurements of the mandible on panoramic radiographs. Oral Surg. Oral Med. Oral Pathol. Oral Radiol. Endod., 86(2):242-8,1998.

Fallon, S. D.; Fritz, G. W. \& Laskin, D. M. Panoramic imaging of the temporomandibular joint: an experimental study using cadaveric skulls. J. Oral Maxillofac. Surg., 64(2):223-9, 2006.

Farman, A. G. Panoramic radiographic images and the prediction of asymmetry. Dentomaxillofac. Radiol., 35(2):129, 2006.

Gaur, B.; Chaudhary, A.; Wanjari, P. V.; Sunil, M. \& Basavaraj, P. Evaluation of panoramic Radiographs as a Screening Tool of Osteoporosis in Post Menopausal Women: A Cross Sectional Study. J. Clin. Diagn. Res., 7(9):2051-5, 2013.

Habets, L. L.; Benzuur, J. N.; van Ooij, C. P. \& Hansson, T. L. The orthopantomogram, an aid in diagnosis of temporomandibular joint problems. I. The factor of vertical magnification. J. Oral Rehabil., 14(5):475-80, 1987.

Hallman, M.; Hedin, M.; Sennerby, L. \& Lundgren, S. A prospective 1year clinical and radiographic study of implants placed after maxillary sinus floor augmentation with bovine hydroxyapatite and autogenous bone. J. Oral Maxillofac. Surg., 60(3):277-84, 2002.

Larheim, T. A.; Svanaes, D. B \& Johannessen, S. Reproducibility of radiographs with the orthopantomograph 5: tooth-length assessment. Oral Surg. Oral Med. Oral Pathol., 58(6):736-41, 1984.

Laster, W. S.; Ludlo, J. B.; Bailey, L. J. \& Hershey, H. G. Accuracy of measurements of mandibular anatomy and prediction of asymmetry in panoramic radiographic images. Dentomaxillofac. Radiol., 34(6):343$9,2005$.

Lundström, A. \& Lundström, F. The Frankfort horizontal as a basis for cephalometric analysis. Am. J. Orthod. Dentofacial Orthop., 107(5):53740, 1995.

Mazzonetto, R. \& Allais de Maurette, M. Radiographic evaluation of alveolar distraction osteogenesis: analysis of 60 cases. J. Oral Maxillofac. Surg., 63(12):1708-11, 2005.

McDavid, W. D.; Tronje, G. \& Welander, U. A method to maintain a constant magnification factor throughout the exposure of rotational panoramic radiographs. Dentomaxillofac. Radiol., 18(4):160-8, 1989.

Mohamed, A.; Nataraj, K.; Mathew, V. B.; Varma, B.; Mohamed, S.; Valappila, N. J. \& Meena, A. S. Location of mental foramen using digital panoramic radiography. J. Forensic Dent. Sci., 8(2):79-82, 2016.

Rondon, R. H.; Pereira, Y. C. \& do Nascimento, G. C. Common positioning errors in panoramic radiography: A review. Imaging Sci. Dent., 44(1):16, 2014.

Roth, F. S.; Kokoska, M. S.; Awwad, E. E.; Martin, D. S.; Olson, G. T.; Hollier, L. H. \& Hollenbeak, C. S. The identification of mandible fractures by helical computed tomography and panorex tomography. $J$. Craniofac. Surg., 16(3):394-9, 2005.

Sandhu, S. \& Kaur, T. Radiographic study of the positional changes and eruption of impacted third molars in young adults of an Asian Indian population. J. Oral Maxillofac. Surg., 66(8):1617-24, 2008.

Schulze, R.; Krummenauer, F.; Schalldach, F. \& D’Hoedt, B. Precision and accuracy of measurements in digital panoramic radiography. Dentomaxillofac. Radiol., 29(1):52-6, 2000.

Sedaghatfar, M.; August, M. A. \& Dodson, T. B. Panoramic radiographic findings as predictors of inferior alveolar nerve exposure following third molar extraction. J. Oral Maxillofac. Surg., 63(1):3-7, 2005.

Tohnak, S.; Mehnert, A. J.; Mahoney, M. \& Croizer, S. Synthesizing dental radiographs for human identification. J. Dent. Res., 86(11):1057-62, 2007.

Treister, N.; Sheehy, N.; Bae, E. H.; Friedland, B.; Lerman, M. \& Woo, S. Dental panoramic radiographic evaluation in bisphosphonate-associated osteonecrosis of the jaws. Oral Dis., 15(1):88-92, 2009.

Turp, J. C.; Vach, W.; Harbich, K.; Alt, K. W. \& Strub, J. R. Determining mandibular condyle and ramus height with the help of an Orthopantomogram--a valid method? J. Oral Rehabil., 23(6):395-400, 1996.

Yitschacky, M.; Haviv, Y.; Aframian, D. J.; Abed, Y. \& Redlich, M. Prediction of premolar tooth lengths based on their panoramic radiographic lengths. Dentomaxillofac. Radiol., 33(6):370-2, 2004.

Corresponding author:
Janneth Zúñiga

Oral and Maxillofacial Surgeon

M. Sc. in Biomedical Sciences

Professor at the Universidad del Valle

Department of Morphology

Calle 4B No. 36 - 00 Ed. 116

Departamento de Morfología

Cali

COLOMBIA

Phone/fax: 57- 2- 5185627

Mobile phone: 57- 3116770983

Email:cxmaxilofacial@drajannethzuniga.com

Received: 22-09-2016

Accepted: 24-11-2016 